\title{
Agaricus bisporus-derived glucosamine hydrochloride facilitates skeletal injury repair through Bmp signaling in zebrafish osteoporosis model
}

Wei Peng ${ }^{\mathrm{a}, \mathrm{b}, 1}$, Wenjuan Zhang ${ }^{\mathrm{a}, \mathrm{c}, 1}$, Qici Wu ${ }^{\mathrm{a}, \mathrm{b}}$, Tingting Jia ${ }^{\mathrm{a}, \mathrm{b}}$, Jiarui Sun ${ }^{\mathrm{a}, \mathrm{b}}$, Zhichao Lin ${ }^{\mathrm{a}, \mathrm{b}}$, Shunyou Cai ${ }^{\mathrm{d}}$, Gulimiran Alitongbieke ${ }^{\mathrm{a}, \mathrm{b}}$, Yixuan Chen ${ }^{\mathrm{a}, \mathrm{b}}, \mathrm{Yi} \mathrm{Su}{ }^{\mathrm{a}, \mathrm{b}}$, Jinmei Lin ${ }^{\mathrm{a}, \mathrm{b}}$, Lisheng Cai Yuqin Sun ${ }^{e}$, Yutian Pan ${ }^{a, b, *}$, Yu Xue a,b,**

\section{Supplementary Information}




\section{Contents}

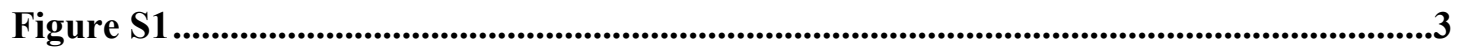

Figure $\mathrm{S2}$..............................................................................................................................................

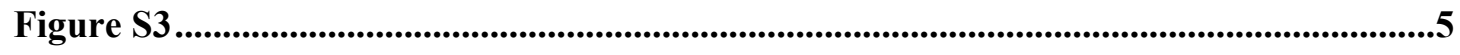




\section{Figure S1}

\section{Figure S1}

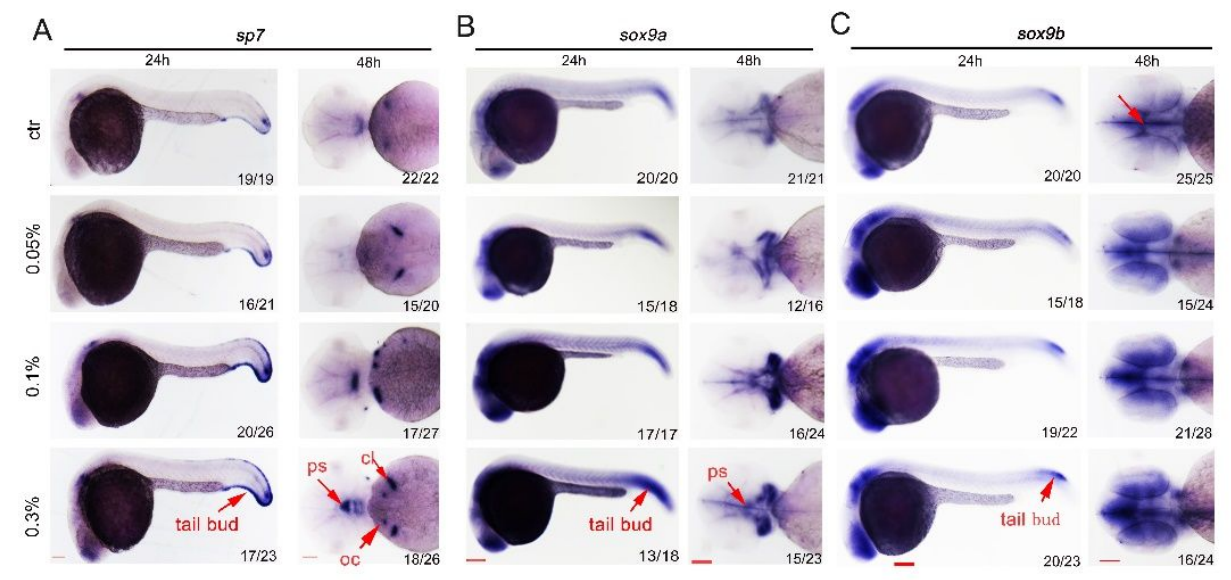

Figure S1 GAH promotes spatial and temporal expression patterns of $\operatorname{sp} 7$ (A), $\operatorname{sox} 9 a(\mathrm{~B})$, and $\operatorname{sox} 9 b(\mathrm{C})$ after treatment with different concentrations of GAH. Lateral view of $24 \mathrm{hpf}$ embryos and ventral view of 48 hpf embryos. Arrows indicate: cl, cleithrum; ps, parasphenoid; oc, occitipal. Scale bars: $100 \mu \mathrm{m}$. 


\section{Figure S2}

Figure S2

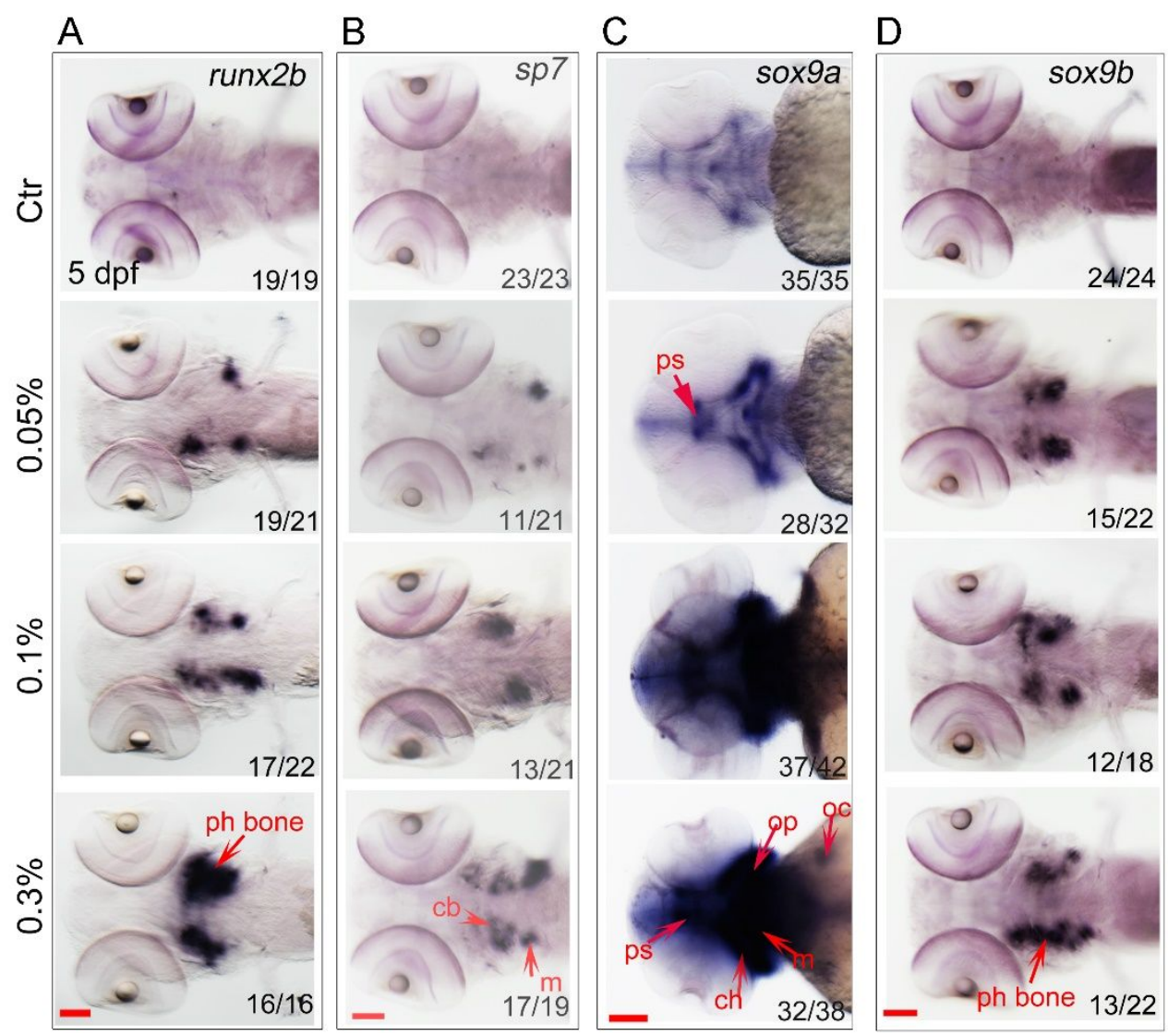

Figure S2 Spatial and temporal expression patterns of $\operatorname{runx} 2 b(\mathrm{~A}), \operatorname{sp} 7(\mathrm{~B}), \operatorname{sox} 9 a(\mathrm{C})$, and $\operatorname{sox} 9 b$ (D) after treatment with different concentrations of GAH at 5 dpf. Arrows indicate: ph bone, perichondral bone; m, mandibular arch; cb, ceratobranchial; ps, parasphenoid; ch, ceratohyal; op, operculum; oc, occitipal; pq, palatoquadrate. Scale bars: $100 \mu \mathrm{m}$. 


\section{Figure S3}

Figure S3

A

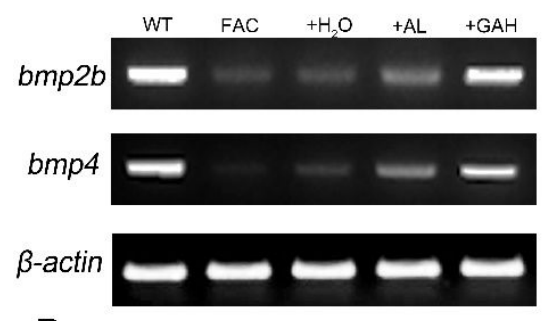

$D_{\text {fin }}$

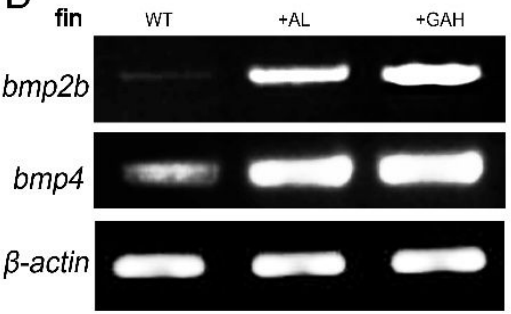

B

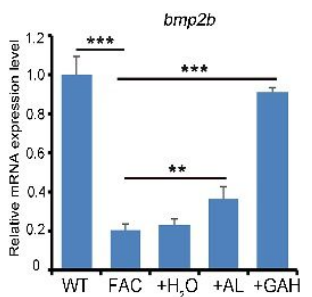

$\mathrm{E}$
C

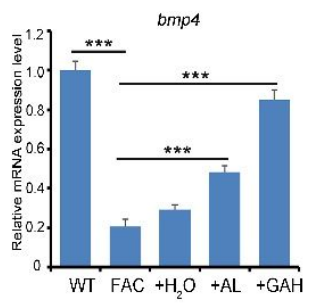

$\mathrm{F}$
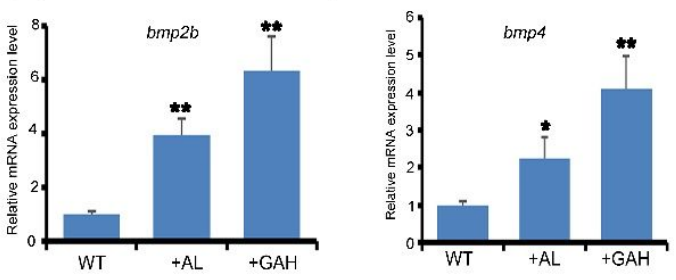

Figure S3 Expression of bmp genes are enhanced after GAH treatment in 10 dpf larvae and in the regenerating fin of adult zebrafish. (A) Amplified bands of $b m p 2 b$ and $b m p 4$ by semi-quantitative PCR in different treatment groups as indicated in $10 \mathrm{dpf}$ larvae. $\beta$-actin: reference gene. (B-C) Quantitative data from A. (D) Amplified bands of $b m p 2 b$ and $b m p 4$ by semi-quantitative PCR in different treatment groups as indicated in the adult regenerating fin. $\beta$-actin: reference gene. (E-F) Quantitative data from D. $* P<0.05, * * P<0.01, * * * P<0.001$. 
